\title{
El temprano fin del siglo XX: dinámicas internas y tendencias mundiales en los proyectos neoliberales en Chile y México (1973-1994)
}

The premature end of the 20th century: internal dynamics and global trends in neoliberal projects in Chile and Mexico (1973-1994)

\section{Pablo Cuevas Valdés*}

Resumen: El artículo estudia comparativamente la instalación de proyectos neoliberales en Chile y en México, como parte del proceso de cambio en los patrones de reproducción de capital en la región, destacando el diálogo entre el contexto global y las dinámicas políticas y económicas particulares. La comparación entre los dos casos permite comprender diferencias entre la manera en que ocurren estos procesos, como el diferente ritmo y uso de la violencia en la imposición de estos proyectos.

Palabras clave: neoliberalismo, proyectos de clases, crisis, patrones de reproducción de capital.

\begin{abstract}
The article comparatively studies the installation of neoliberal projects in Chile and Mexico, as part of the process of change in capital reproduction patterns in the region, highlighting the dialogue between the global context and the particular political and economic dynamics. The comparison between the two cases allows understanding differences between the way in which these processes occur, such as the different rhythm and use of violence in the imposition of these projects.
\end{abstract}

Keywords: neoliberalism, class projects, crisis, capital reproduction patterns

Recibido: 6 julio 2018 Aceptado: 22 agosto 2018

\footnotetext{
${ }^{*}$ Chileno. Doctor en Estudios Latinoamericanos, por la Universidad Nacional Autónoma de México (UNAM); Maestro en Ciencias Sociales, por la Facultad Latinoamericana de Ciencias Sociales, Sede México (FLACSO-México); Especialista en Historia del Pensamiento Económico (Facultad de Economía-UNAM); y Licenciado en Antropología por la Universidad Academia de Humanismo Cristiano (UAHC-Chile) CE: pablocuevasvaldés@gmail.com
} 


\section{Introducción1}

En América Latina, los últimos tres lustros del siglo XX estuvieron marcados por el ascenso y hegemonía de los proyectos neoliberales. Dos casos emblemáticos dentro de la región, que sirvieron de precedente y "modelo" a las élites de otros países, fueron, por una parte, el temprano y radical experimento neoliberal en Chile desde 1973, y el comienzo del desmonte del enorme Estado corporativo mexicano luego de la crisis de la deuda desde 1982. El presente artículo estudia de forma comparativa la manera en que estos proyectos se hicieron carne en estos dos países a través de la instalación de modelos económicos -y políticos- neoliberales, intentando destacar los elementos globales y determinantes sistémico-mundiales del triunfo de estos proyectos de clase, y distinguiéndolos de las dinámicas políticas y contextos particulares donde ocurren y se posibilitan estas transformaciones concretas. La comparación de estos dos casos de estudio permite responder lo que constituye la pregunta central del artículo. ¿Cómo se explica que dos proyectos político-económicos de contenidos tan similares se implementasen mediante procesos de cambio tan distintos en cuanto a ritmos, gradualidad y formas del uso de la violencia de Estado? Al respecto, el artículo explora la hipótesis de que estas diferencias se relacionan con las particularidades que asumen los acuerdos de clase propios de los desarrollismos de la posguerra, ello debido a las diferentes características de las clases sociales en cada uno de los países, ancladas en las diferencias que asumen los patrones de reproducción del capital en cada país. Al respecto, cobra relevancia el papel de las lógicas institucionalizadas por medio de las cuales opera el poder en contextos de crisis, aunque sin perder de vista que éstas vehiculizan relaciones de poder cuyo soporte no es la institucionalidad, sino los intereses concretos de los grupos sociales y sus vínculos con el sistema productivo.

El artículo se desarrolla siguiendo un método histórico y comparativo, ${ }^{2}$ a partir de un corpus documental principalmente secundario, conformado por estudios e investigaciones provenientes de diferentes campos de las ciencias sociales y humanas, incorporando además algunos datos estadísticos y documentos primarios editados y publicados. La exposición se estructura cronológicamente, destacando la comparación entre los elementos comunes y generales en ambos casos, y acentuando las especificidades y dinámicas particulares. Por las dimensiones y alcances del artículo, la comparación no profundiza demasiado en las dinámicas históricas particulares, sino más bien se centra en algunos elementos generales. De esta manera, el análisis se propone no romper el diálogo entre lo abstracto y lo concreto, entre las tendencias globales y las particulares, y aportar con una lectura general de estos procesos desde un punto de vista latinoamericano y crítico. En consecuencia, no pretende aportar con una descripción acuciosa de los casos -cuestión ampliamente lograda en varias de las fuentes

\footnotetext{
1 Parte del trabajo que el presente artículo refleja, es producto del proyecto de tesis doctoral de su autor, La "ventaja" del asalariado rural latinoamericano: el trabajo silvoagropecuario en el actual patrón de acumulación de capital a través de los casos de Chile y México, México, UNAM, 2017, que fue realizado gracias al apoyo económico de CONACyT, México. El autor agradece especialmente al concejo editorial de la revista Izquierdas y a los evaluadores del artículo, pues de su acuciosa lectura, observaciones y sugerencias el presente texto se benefició ostensiblemente.

2 De manera general, en las ciencias sociales y humanas por método comparativo se entiende la búsqueda de similitudes y diferencias entre dos configuraciones cuyo propósito es indagar en sus estructuras a fin de establecer relaciones de vinculación, causalidad, linaje o conexión entre éstas o una estructura general de la que éstas derivan o las contiene.
} 
citadas y en otros trabajos de mayor extensión- sino más bien, intenta contribuir desde la compresión general, reflexión e interpretación teórica de la historia reciente de nuestra región.

En esta línea, se estudia, de manera general, la instalación de estos modelos neoliberales como una fase -sin duda determinante- contenida en un proceso mayor: el cambio en los "patrones de reproducción del capital" 3 en la región. Esta lectura procesual es realizada en relación al nuevo orden económico internacional y al nuevo equilibrio global de fuerzas entre el mundo del capital y del trabajo que surge desde la década de 1970, sin por ello perder de vista un análisis de la dinámica de clases y sectores de clases al interior de cada país. ${ }^{4}$

${ }^{3}$ El concepto de "patrón reproducción capital" permite caracterizar la reproducción del capital en tiempos históricos y espacios geográficos determinados, esto es, las características del ciclo del capital, de acuerdo a los distintos sectores o ramas que el capital privilegia y la forma concreta que asume ese ciclo del capital. La descripción de un patrón de reproducción de capital concreto supone caracterizar las transformaciones que sufre el capital a través del ciclo del capital dinerario (D-M... P....M'-D', donde $\mathrm{D}=$ dinero, $\mathrm{M}=$ mercancía, $\mathrm{P}=$ =proceso de producción, M'=mercancía incrementada, y D'=dinero incrementado) señalando las particularidades que asume la metamorfosis del capital en cada fase. El concepto refleja, a grandes rasgos, cuál es el origen del capital, cuales son los sectores que el capital privilegia (los sectores eje) y de qué forma se realiza esa producción (mercado interno, mercado externo, sectores del mercado, etc.) en un determinado momento histórico. Al respecto puede consultarse el libro de Jaime Osorio, Teoría marxista de la dependencia, México, ITACA - UAM-X, 2016. Por su parte, es central aquí mantener la distinción entre la noción de "modelo económico" -entendido como un conjunto articulado de políticas que "modelan" un determinado comportamiento de la economía- del concepto más estructural, concreto y descriptivo de "patrón de reproducción de capital". Un modelo no es sino una representación abstracta que proyecta una realidad determinada y, por su parte, un patrón es una regularidad observada.

4 Para esclarecer la pregunta e hipótesis señalada más atrás, es necesario señalar algunos aspectos generales del concepto de clase social, y en concreto, la posibilidad de acuerdos, alianzas o entre clases y sectores dentro de éstas. En concepto y el análisis de las clases sociales enfatiza el aspecto vinculante entre los seres humanos en la producción en su existencia, puesto que los agrupamientos humanos que las constituyen se diferencian a partir de las relaciones que establecen con ese fin. La noción de clases sociales se desprende del análisis de las categorías fundamentales del modo de producción capitalista. Marx la retoma de la economía política clásica en donde, desde Petty, pasando por Smith y Ricardo, la clase era una categoría central, involucrada en sus teorías del valor, puesto que aludía a los grupos sociales asociados a los distintos factores de la producción (tierra, capital y trabajo), y por tanto a la distribución de la riqueza entre éstos. Para Marx: "Los propietarios de mera fuerza de trabajo, los propietarios de capital y los terratenientes, cuyas respectivas fuentes de ingreso son el salario, la ganancia y la renta de la tierra, esto es, asalariados, capitalistas y terratenientes, forman las tres grandes clases de la sociedad moderna, que se funda en el modo capitalista de producción." ((El Capital. Tomo III/Vol. 8, México, Siglo XXI, 1986, p. 1123). Sin embargo, la existencia de tres clases refiere al nivel de abstracción más elevado: al del modo de producción. En efecto, el mismo Marx aclara que, ni siquiera en Inglaterra - expresión más "pura” del capitalismo por los años en que escribe- “...se destaca con pureza esa articulación de clases" y en seguida explica que también allí "...grados intermedios y de transición (aunque incomparablemente menos en el campo que en las ciudades) encubren por doquier las líneas de demarcación" (Marx, idem). Ello es una clara indicación de Marx respecto de que, al acercarse a un nivel de concreción histórico mayor, es decir, en el análisis de casos históricos particulares, debe complejizarse el análisis de las clases. En el fondo, lo que define a estos agrupamientos humanos es su ubicación en "...un sistema de producción históricamente determinado, por las relaciones en que se encuentran frente a los medios de producción... (Lenin, "Una Gran Iniciativa”, en Lenin, Obras escogidas en tres volúmenes, vol 3, Moscú, Progreso, 1966, p. 232). Esto significa que un análisis de la dinámica de las clases sociales toma en cuenta las particularidades de las modalidades históricas concretas del capitalismo, e incluye los conflictos no sólo entre las clases, sino entre los sectores de clase, como, por ejemplo, sectores de la burguesía o los trabajadores vinculados a uno u otros sectores del capital (industrial, financiero, nacional, extranjero, pequeño, grande, etc). La dinámica de estos agrupamientos se encuentra vinculada a los conflictos concretos que se suscitan en diferentes momentos y modalidades del capitalismo. De esta manera, el concepto abstracto de, por ejemplo, burguesía, alcanza concreción al referir a la burguesía de Chile o de México durante el periodo de sustitución de importaciones. Ambas son burguesías, pero cada una llena de contenidos el concepto en función de la dinámica concreta y conflictos que desarrolla el capital en esos espacios y momentos determinados. Una burguesía particular tampoco es un bloque único, ésta, al expresar intereses de diferentes sectores, en determinadas circunstancias pueden entrar en conflicto, así como también, determinados sectores de la 
Ello es a contracorriente de las ampliamente difundidas lecturas que ven en el neoliberalismo y en el voluntarismo de las instituciones internacionales y actores históricos, el origen directo de las grandes transformaciones que marcan el fin del siglo XX en la región. Para esto, se retoman los conceptos de una clásica y reemergente escuela de pensamiento crítico latinoamericano, esta es, la llamada teoría de la dependencia. ${ }^{5}$

El texto se estructura en tres partes. En una primera, de carácter más general, se pasa revista al contexto económico internacional en que se dan estas transformaciones, poniendo énfasis en las relaciones entre éste y los casos estudiados, a fin de no perder de vista su vínculo y evitando una representación de "lo externo" como ajeno a "lo interno". Cobra especial sentido allí la conexión entre la crisis global de acumulación del capital y la crisis local de los proyectos industriales-desarrollistas. Por otro lado, en una segunda parte, se aborda concretamente el caso de ambos países, presentando de manera global los principales rasgos de la crisis del previo patrón industrial de reproducción de capital y su modelo desarrollista, y las necesidades de los sectores dominantes de adecuar el modelo de desarrollo a los nuevos requerimientos de la reproducción del capital. Se presenta también, de manera sintética, la dinámica en que ocurre la implantación de estos modelos neoliberales, siguiendo un esquema de exposición comparativo y cronológico, y problematizando cada caso con sus dinámicas particulares y vinculándolo con el contexto internacional. Por último, y a modo de cierre, en una tercera parte se retoman las interrogantes planteadas -de varias formas ya abordadas- destacando en su réplica la síntesis entre tendencias mundiales y las dinámicas internas en el triunfo de los proyectos neoliberales en Chile y México.

\section{El contexto mundial: crisis de acumulación y cambio de fase en el capitalismo}

Desde mediados de la década de 1970 hasta mediados de la de 1980 se asiste en América Latina a un periodo de transición, desde el viejo patrón industrial de reproducción del capital, hacia el nuevo patrón exportador de especialización productiva, vigente hasta hoy. ${ }^{6}$ Este

burguesía pueden aliarse a sectores de la clase trabajadora para impulsar proyectos específicos. Es allí cuando aparecen diferentes acuerdos, pactos explícitos o implícitos, compromisos institucionalizados formal o socialmente, entre sectores de diferentes clases sociales. Estas configuraciones guardan una relación -no mecánica- con las configuraciones específicas de la reproducción del capital

5 Por "teoría de la dependencia" se ha referido a una multiplicidad de enfoques teóricamente heterogéneos que, principalmente entre las décadas de 1960 y 1980, referían a la condición de dependientes de los países latinoamericanos. Pueden encontrarse dos grandes grupos de propuestas que hablaron de "dependencia", por un lado, los de tipo estructuralista, vinculados al pensamiento de la CEPAL, donde destaca el trabajo de Fernando Cardoso, Raúl Prebisch, entre otros. Este grupo hablaba de un "enfoque" de la dependencia y no de una "teoría". Por otro lado, existe desde entonces una postura crítica a la anterior, de raigambre marxista, donde destaca la obra de Ruy Mauro Marini (Dialéctica de la dependencia, México, Era, 1973), la de Adré Gunder Frank, Theotonio Dos Santos (entre otros) y que más recientemente ha continuado su elaboración a partir del trabajo de Jaime Osorio, Adrián Sotelo, entre otros en México (a quienes más adelante se les citará) y con mayores modificaciones, de Claudo Katz (entre otros en Argentina, donde existe un bullido debate entre marxistas dependentistas y antidepedentistas, entre los economistas críticos), por mencionar a los más conocidos. A diferencia de la corriente cepalina, la corriente marxista reivindica como teoría a su formulación, dado que plantea a la dependencia como una condición estructural propia de la configuración de un sistema mundial capitalista, y no como una "situación" fácilmente modificable. ${ }^{6}$ El patrón de reproducción de capital industrial, vigente en América Latina desde la década de 1940 hasta la década de 1970-1980, aproximadamente, se caracterizó, a muy grandes rasgos, por economías donde los sectores eje del capital eran industriales y cuyos mercados principales se encontraba en el ámbito interno. El patrón de reproducción 
cambio ocurre en el contexto de una reorganización de la economía mundial en su totalidad, estableciéndose una nueva división internacional del trabajo y configurándose un cambio de fase en el capitalismo mundial. Este nuevo escenario modificará profundamente las economías nacionales, transformando las características generales del ciclo del capital.

La crisis de la etapa de postguerra fue global, se manifestó -de manera principal- en una reducción de la tasa global de ganancias del capital, la que cae a partir de $1965 .{ }^{7}$ La disminución de esta tasa genera la contracción de la inversión y por lo tanto, una sobreacumulación de capital. ${ }^{8}$ Como tendencia global, ya entrada la década de 1970 entraron en crisis aquellas economías que, en su ámbito nacional, de una u otra forma incluían a los sectores trabajadores como consumidores y que manejaban el conflicto de clase mediante una política keynesiana, entre las cuales, se encontraban las de varios países de la región, como Chile y México. ${ }^{9}$

Los "compromisos de clase" entre el capital y el trabajo, sobre los que se basaba el orden que permitía la reproducción del capital, en la mayoría de estas economías, suponían una participación importante y creciente del trabajo en las ganancias, lo que a su vez determinaba una menor participación del capital en ellas. Y ello no fue problema y logró contener el turbulento "clima social" del siglo XX mientras estos esquemas mantuvieron el crecimiento económico. Pero todo cambió cuando, a mediados de la década de 1970, se reducen drásticamente las ganancias del capital.10

Los mecanismos de subordinación de la fuerza de trabajo que fueron exitosos durante la posguerra, generaron, a la larga, una fractura de los mecanismos de acumulación de capital. Desde el punto de vista del capital, debía eliminarse las trabas para su reproducción, lo cual exigía, por una parte, un cambio en estos mecanismos de subordinación del trabajo, y por otra, la modificación en la organización de la producción y circulación de mercancías y capitales a nivel mundial. Esta reorganización de la economía mundial requiere lo que Harvey ${ }^{11}$ denomina como "ajustes espacio-temporales", por medio de los cuales el gran capital internacional logra evitar la devaluación de sus activos en el contexto de la crisis, buscando nuevas formas de

de capital exportador de especialización productiva -vigente a partir de un variable periodo de transición, luego de las reformas neoliberales, entre las décadas de 1980 y 1990- se caracteriza, a muy groso modo, por economías que producen aquello en lo que tienen ventajas comparativas y competitivas mundiales para el mercado internacional. Estas ventajas pueden estar tanto en productos primarios, como en algunos secundarios.

${ }_{7}$ Al respecto, puede consultarse a: Ruy Mauro Marini, "Proceso y tendencias de la globalización capitalista", Ruy Muro Marini y Márgara Millán (eds.) La teoría social latinoamericana. Cuestiones contemporáneas. Tomo IV, México, Ediciones el caballito - UNAM, 1996, PP.49-68. Y a David Harvey, "The 'new' imperialism: accumulation by dispossession", en Socialist Register, No. 40, 2004, pp. 64-87.

${ }^{8}$ Harvey, Idem.

9 Dentro de América Latina, las economías que incluyeron a los trabajadores como consumidores durante la posguerra, son aquellas que tuvieron un vuelco de su producción hacia la industria, es decir, aquellas en las que operó un patrón industrial. Bulmer-Thomas introduce una distinción entre los países de la región en los que, para el periodo, se puede hablar de una economía industrial y aquellos que continuaron centrado su proceso de acumulación en la exportación primaria. Argentina, Brasil, Chile, Colombia, México y Uruguay son los seis países en los que la industria se tornó en el sector de vanguardia para la década de 1950, los que adoptaron el modelo "hacia adentro", luego de un periodo previo de desarrollo industrial desde la década de 1930. En los demás catorce países de la región, al no efectuarse ese proceso de proto-industrialización, la acumulación continuó en función de la economía exportadora. Por lo tanto, se entiende que al hablar de patrón industrial latinoamericano se hace alusión a los primeros seis países. Ver Victor Bulmer-Thomas, La historia económica de América Latina desde la Independencia, México, FCE, 2003

10 Ver a David Harvey, Breve historia del neoliberalismo, Madrid, Akal, 2007.

${ }^{11}$ Harvey, "The 'new' imperialism..." op cit, pp. 64-87. 
producción de plusvalía y de extracción de plusvalía extraordinaria, lo cual hace mediante el desplazamiento geográfico de las inversiones, y su aplazamiento.

Por lo tanto, la recuperación de la tasa de ganancia en términos capitalistas reclamaba que el capital golpeara más fuertemente al trabajo, tanto directamente, en el salario y los derechos laborales conquistados a lo largo del siglo XX, como indirectamente, modificando la institucionalidad estatal -que, de una u otra forma, tendía a dar concesiones a sectores del movimiento obrero- alterando los esquemas nacionales de protección de algunos sectores del capital.

Es aquí cuando hace su aparición en la historia el llamado "neoliberalismo", en tanto ideología y esquema propositivo articulado de salida de esta crisis. Desde un punto de vista político, el neoliberalismo expresaba en términos "técnicos" los intereses de los sectores del gran capital y el sector financiero a nivel mundial, y por lo tanto, proponía un tipo particular de salida a esa crisis -no la única como arrogantemente los neoliberales pretendían, aunque sí posiblemente la salida más capitalista-12 expresando los requerimientos de política económica adecuados para facilitar la reproducción del gran capital mundial y recuperar de esa forma la tasa de ganancia, para lo cual era necesario destruir esos "acuerdos de clase" y golpear al mundo del trabajo. Y ello fue posible porque el neoliberalismo si bien se presenta como un grupo o paquete de políticas económicas, expresa una concepción completa de la sociedad, una utopía de clase, que se explica en el contexto de este proceso histórico. El eje de esta concepción es que el mercado -dotado de cierto carácter "natural"- es la única institución capaz de asignar eficazmente los recursos sociales y de articular las relaciones entre los agentes económicos, empresarios, consumidores y trabajadores, por tanto, su funcionamiento no debe verse obstruido por intervención -“torpe"- del Estado, el cual por el contrario debe mantener una institucionalidad que favorezca el desarrollo de las capacidades de los individuos, a partir de la protección de sus libertades negativas, es decir, que procure que no se impida el ejercicio de éstas. ${ }^{13}$

La recuperación de la tasa mundial de ganancia exigía centralizar los medios de trabajo, eliminando los menos eficientes -usualmente los representados por pequeños y medianos capitales, variablemente resguardados por los esquemas proteccionistas de las economías nacionales- $y$, además, reducir la fuerza de trabajo que operaba en las empresas que sobrevivieran a la reestructuración, aumentando la intensidad del trabajo de la fracción de trabajadores restante. Como consecuencia, tiende a aumentar la parte de las ganancias que corresponde a los propietarios de los medios de producción, lo que favorece una elevación de la tasa de inversión y la producción en grandes unidades económicas, lo que, a su vez, incentiva

\footnotetext{
12 Por ejemplo, un capitalismo de Estado donde la inversión no dependiera de la tasa de ganancia también podría haber sido una solución a esa crisis, aunque claramente habría sido una solución "menos capitalista".

13 David Harvey lo sintetiza de la siguiente manera, señalando que es “... ante todo, una teoría de prácticas políticoeconómicas que afirma que la mejor manera de promover el bienestar del ser humano consiste en no restringir el libre desarrollo de sus capacidades y de las libertades empresariales del individuo, dentro de un marco institucional caracterizado por derechos de propiedad fuertes, mercados libres y libertad de comercio." Harvey, "Breve historia..." Op Cit, p.6. De acuerdo a Friedrich Von Hayek, el papel del Estado debe restringirse -y no ir más allá- de la preservación del marco institucional apropiado para el desarrollo de las libertades del individuo, protegiendo derechos individuales que preceden a la figura misma del Estado. Ello se enlaza con una teoría y visión de la sociedad humana de carácter individualista, que presenta a las instituciones colectivas sociales como producto de la interacción libre humana y no del diseño racional (como por ejemplo el leguaje, el derecho natural, y por supuesto, el mercado) estando su completa intelección -y menos aún control, intervención y regulación- lejos de una racionalidad humana limitada. Friedrich Hayek, Camino de servidumbre, Madrid, Alianza, 2007
} 
la introducción de innovaciones tecnológicas. Pero simultáneamente, ello implica que los sectores de punta del capital deben reorientarse mayormente hacia el sector de bienes suntuarios, dado que la cesantía y la falta de ingresos de los trabajadores no permitirían la realización del capital en bienes de consumo popular. Esto exigía también ampliar ese espacio de demanda suntuaria, dado que, pese a que aumentaban los ingresos del capital, las fronteras nacionales y los esquemas de política proteccionistas lo mantenían muy restringido y, por tanto, se tornaba necesario desbloquear la circulación internacional de mercancías, lo que permitiría el "anhelado" crecimiento económico sin un correlativo aumento del empleo. Esto último exigía también el sometimiento del mundo del trabajo. ${ }^{14}$

Y derrotando al movimiento obrero, las empresas pudieron recurrir con más libertad, y con menos trabas, a la tercerización y a la flexibilización laboral, lo que les permitió recortar una parte de los ingresos de los trabajadores y transformarlos en ganancias del capital.

Simultáneamente, la mayor centralización de los medios de trabajo favorece una revolución tecnológica en la producción mundial, que ya venía desarrollándose años antes de la crisis. Estos cambios tecnológicos permiten altos grados de estandarización en la producción de partes y componentes, y posibilita a su vez la fragmentación de la producción de esos componentes entre empresas, filiales y países. En efecto, “...la producción mundial se caracteriza hoy por una creciente homogenización en materia de capital constante fijo y circulante." 15 De esta manera, las empresas desplazan algunos procesos productivos a países de la periferia, donde los salarios son más bajos, pero donde, sin embargo, la productividad del trabajo no es inferior debido a la generalización de algunas tecnologías productivas.

Estas tendencias generan una nueva división internacional del trabajo, la que, como bien señala Marini,16 operaría en el plano de la fuerza de trabajo y ya no a través de la posición ocupada en el mercado mundial por la economía nacional en donde el trabajador se desempeña. El trabajador participa entonces, cada vez más, en un "ejército industrial globalizado", a partir del grado de educación y calificación productiva. ${ }^{17}$

Esta nueva división internacional del trabajo surgida a partir de la supresión de las barreras que fragmentaban el mercado mundial y que ponían obstáculos al flujo de mercancías, elimina también las trabas y diferencias nacionales que impiden que la Ley del valor opere libremente. En este nuevo "libre mercado mundial" los valores pueden compararse unos con

\footnotetext{
14 Marini lo señala de la siguiente manera: "Para imponer ese patrón de desarrollo económico que combina crecimiento y desempleo fue necesario quebrar la tesis de la resistencia del movimiento obrero, lo que dio lugar a las batallas memorables que se libraron a fines de los años setenta y principios de los ochenta, la más dura de las cuales fue la que enfrentó a Margaret Thatcher con los mineros ingleses, al inicio de su gobierno. Los enfrentamientos se repitieron en Estados Unidos, Alemania, Francia e Italia, principalmente, y provocaron, junto con el aumento del desempleo, el debilitamiento de los sindicatos. Es así como entre 1970 y 1990 el índice de sindicalización de la masa laboral se redujo de 23\% a 17\% en Estados Unidos, de $42 \%$ a 40\% en Gran Bretaña, de 22\% a 10\% en Francia y de 37\% a 28\% en Japón.” Marini, “Proceso y tendencias...”, Op Cit, p. 56

15 Marini, Ibid, p.61.

16 Marini, Idem.

17 Sin embargo, esta generalización de tecnologías no deja de ser parcial, pues, los países capitalistas desarrollados conservan el monopolio de la generación de tecnología y el control sobre la transferencia de actividades industriales en función de las ganancias del capital, lo que genera una división internacional del trabajo que adquiere una forma muy definida, donde las actividades de diseño, investigación y en general, las de mayor "valor agregado", permanecen en los países centrales, mientras otras fases de la producción que utilizan más fuerza de trabajo, y que deterioran más el medio ambiente, se desagradan a países dependientes, que poseen la tecnología justa para desempeñar esa función.
} 
otros, con menores distorsiones. Y una consecuencia de esto es que aumenta la importancia del trabajador como fuente de ganancias extraordinarias.

El capital busca explotar las diferencias nacionales, pero ya no aquellas que creaba el proteccionismo en el pasado en busca de hacer uso de un mercado interno cautivo, sino las ventajas de utilizar una fuerza de trabajo al menor precio posible, para producir mercancías que se realizarán en el mercado mundial. Esto genera economías nacionales exportadoras y con una mayor tendencia a la superexplotación del trabajo, dado que la reducción de los ingresos de la masa trabajadora no repercute en las ganancias del capital como una reducción directa en el mercado de sus productos. El consumo del trabajador se desvincula de la producción, y en efecto, la violación del valor de la fuerza de trabajo se vuelve un fenómeno sumamente característico de la extracción de plusvalía en la nueva fase capitalista, predominado en los países dependientes, pero extendiéndose incluso hasta los países centrales ${ }^{18}$, aunque no llegando a definir la producción de plusvalía de las economías desarrolladas.

En efecto, la proliferación de mecanismos mediante los cuales el capital expolia a toda la "sociedad" y se apodera más allá de la plusvalía que produce, permiten que se hable, en la actual fase del capitalismo, de una "acumulación por desposesión" como medio de recuperación de esta tasa de ganancia. ${ }^{19}$

La forma que adquiere el sistema crediticio y financiero merece particular atención en la fase actual del capitalismo mundial, sobre todo en lo que a acumulación por desposesión refiere. Ya Lenin, Hilferding y Luxemburgo llamaron la atención respecto de que éste jugaba un rol clave en la depredación, fraude y robo, pero en la fase actual se torna un mecanismo clave, junto a nuevas formas de acumulación por desposesión. ${ }^{20}$

En efecto, la centralidad del sector financiero en la nueva fase capitalista es una de las principales características de ésta, y su renovada hegemonía se relaciona con las características de la crisis de la fase anterior. La tendencia a la baja en la tasa de ganancia en los sectores productivos desde fines de la década de 1960 provocó una paulatina migración de los capitales hacia el sector financiero, el que comenzó a adquirir desde esos años mayor poder, aunque limitado por una importante regulación a favor de los sectores productivos. La influencia del sector financiero -particularmente el estadounidense, afligido por la valorización de las monedas de Europa Occidental y Japón- es determinante en la modificación de las reglas del comercio internacional. Desde 1971 se rompen los acuerdos de Bretton Woods y los tipos de cambio fijo respaldados en oro dan paso a un sistema de tipos de cambio flotantes. El monetarismo de Milton Friedman se impone como nueva ortodoxia en los principales organismos financieros internacionales durante la década de 1970, y desde allí comienza a desregularse el mercado financiero y de capitales. Como veremos, este cambio generará un entorno poco favorable a una política de ampliación del gasto y de endeudamiento de países con modelos keynesianos, como México. Y paralelamente, la gran disponibilidad de divisas depositadas en las instituciones financieras estadounidenses y europeas -producto de las amplias ganancias de los países de la OPEP luego del Shock petrolero de 1973- aportan mayor poder al sector financiero, ofertando créditos a tasas muy competitivas, los cuales son contratados por los países dependientes a tasas variables. Ello determinará, a principios de la

18 Al respecto, una propuesta interesante puede encontrarse en Adrián Sotelo, "Los rumbos del trabajo: Superexplotación y precariedad social en el siglo XXI", México, Porrúa - FCPS-UNAM.

19 Harvey, "“'The 'new' imperialism..." Op Cit, pp. 64-87.

${ }^{20}$ Harvey, Idem. 
década de 1980, cuando las tasas de interés crecieron ostensiblemente, la llamada "crisis de la deuda" que no es sino una muestra de cómo opera el poder financiero y la expoliación de recursos y desposesión a las economías dependientes en el esfuerzo de elevación de la tasa de ganancia de las economías de los países centrales.

Por otro lado, tanto los distintos mecanismos de acumulación por desposesión como una mayor tendencia a la violación del valor de la fuerza de trabajo, ocurren a escala mundial, pero sin embargo, el capitalismo las distribuye geográficamente siguiendo un claro patrón que distingue sus alcances en los países centrales y los dependientes. ${ }^{21}$ Esta observación supone una tesis opuesta a la que han defendido algunos sectores de la nueva "izquierda" en las últimas décadas, a partir de la obra de Michael Hardt y Antonio Negri22.

Por último, cabe una precisión conceptual respecto de la denominación de la etapa actual. A la nueva fase del capitalismo mundial se la ha denominado frecuentemente en alusión al neoliberalismo, como, por ejemplo, "fase neoliberal", "globalización neoliberal", "patrón neoliberal" entre otras nominaciones. Si bien no creemos que ello sea del todo incorrecto, aquí no concordamos con ello. El rol del neoliberalismo en esta fase es similar al del keynesianismo en la fase anterior. El neoliberalismo fue el "pegamento" ideológico que permitió y fomentó la política económica que eliminó las barreras para la reproducción del gran capital mundial en las condiciones históricas del último cuarto del siglo XX. Si bien, en tanto ideología de los sectores conservadores existió a lo largo de todo el periodo de la posguerra, es en el contexto creado por la crisis de acumulación que fue capaz de ofrecer sustento ideológico y "tecnificar" la lucha de clases, proponiendo las medidas que facilitaron la nueva división internacional del trabajo, pero ello, sólo a partir de una particular correlación de fuerzas entre clases y sectores de clase que emerge de las características de la economía de la etapa terminal de la fase capitalista anterior y de la crisis de la misma. ${ }^{23}$ "En este contexto el ascenso del neoliberalismo

\footnotetext{
21 Información estadística que prueba esta afirmación, puede encontrarse en el capítulo 3 de: Pablo Cuevas, La 'ventaja'... Op.Cit.

22 Estos autores postulan que en el mundo globalizado -en las últimas décadas- se ha debilitado la soberanía de todos los Estados Nacionales, lo que trae consigo el fin del "imperialismo" en el que "naciones centrales" concentran la hegemonía económica y política. La hipótesis central de los autores es que la soberanía ha adquirido una nueva forma compuesta por una serie de organismos nacionales y supranacionales, unidos en una lógica única de dominio. A esta unidad los autores la denominan imperio, el que es entendido como “...un aparato descentrado y desterritorializador de dominio que progresivamente incorpora la totalidad del terreno global dentro de sus fronteras abiertas y en permanente expansión." Michael Hardt y Antonio Negri, Imperio, Buenos Aires, Paidós, 2002, p.14. De acuerdo a esta visión, el mundo actual no sería parte de un sistema mundial capitalista, sino de un imperio de formación muy reciente. Esta visión encontró gran acogida en los últimos años del siglo XX, sin embargo, carece de sustento empírico, pues en efecto existe una direccionalidad muy clara en la circulación global de mercancías, primer punto a contrastar si se quisiera rebatir el teorema centro-periferia, como pretenden hacerlo estos autores. Otro autor Atilio Borón, Imperio \& imperialismo: una lectura crítica de Michael Hardt y Antonio Negri, Buenos Aires, Clacsoseñala que la obra de Hardt y Negri se enmarca en el "establishment académico franco-americano", ignorando la literatura que se produce en América Latina, India, África y en otras partes del Tercer Mundo, así como también las discusiones respecto al imperialismo de los autores del marxismo clásico como Hilferding, Luxemburgo, Lenin, Bujarin y Kautsky. Para Borón, todo esto redunda en la elaboración de una visión ideológica del imperio "tal y como él mismo se observa desde su cumbre", visón parcial y unidimensional que desestima la totalidad del sistema.

23 Para Samir Amin, por ejemplo, el "liberalismo económico" en términos puros -libertad absoluta de empresa, sin regulaciones ni imposiciones de ningún tipo- se ha manifestado en los términos de una "utopía liberal”, presente en las aspiraciones de algunos sectores del empresariado mundial. Esta "utopía" ha sido históricamente mediada, en la práctica, por dos factores; la tensión capital-trabajo y las disposiciones internacionales del sistema capitalista mundial. La forma en que se combinan estos dos factores permite la expresión de esa "utopía" económica -en momentos en forma parcial, en otros en forma más pura- y determina las características de la política económica
} 
no es un accidente, sino la palanca por excelencia de que se valen los 269 grandes centros capitalistas para socavar a las fronteras nacionales a fin de despejar el camino para la circulación de sus mercancías y capitales"24. Sin embargo, el neoliberalismo no es ni una fase del capitalismo, ni un patrón de reproducción del capital, ni un "modelo" universal, sino, simplemente "(...)la expresión de una ideología y una política de alcance bastante limitado" 25 en la que se inspiraron la élites de distintos países del mundo para permitir y facilitar un reordenamiento de la economía mundial y la recuperación de una tasa de ganancias decaída, en favor de los sectores del capital dominantes. Esta nueva fase globalizada del capitalismo mundial se expresa en América Latina en patrones de reproducción de capital que tendrán como característica central su carácter exportador, centrado en la especialización productiva.

\section{El neoliberalismo y la política del tránsito hacia un nuevo patrón exportador ${ }^{26}$}

América Latina es el escenario de dos importantes hitos históricos, relevantes para la historia de la nueva fase del capitalismo. El primero, es la aplicación por primera vez en el mundo, de un paquete de políticas neoliberal, en Chile, luego del golpe de Estado de 1973. El segundo es el estallido de la crisis de la deuda en México, en el año 1982, lo que desencadena una serie de hechos que -por diversos motivos- llevan a México y los demás países de la región a aplicar este tipo de política. Ambos hitos, son una muestra del papel que jugó la región en este cambio de fase y en la reestructuración de la economía mundial en su conjunto. Son también efecto no sólo de la expresión de las tenencias del sistema mundial sobre estas economías dependientes, sino además resultado de las propias tendencias de la reproducción del capital al interior de estos países, cuestión que intentaremos dejar de manifiesto.

El patrón de reproducción de capital industrial entra en crisis en toda la región durante la década de 1970, a partir de las fisuras que ya mostraba desde mediados de la década anterior, y el giro hacia una política neoliberal en el que América Latina es "pionera", responde precisamente al agotamiento de ese patrón, y al surgimiento de nuevas tendencias en la reproducción del capital en las economías latinoamericanas. El papel del neoliberalismo consiste en ayudar a que esas tendencias den paso a la conformación de un nuevo patrón de reproducción del capital, un patrón exportador de especialización productiva.

En 1973, mientras en México aún estaba vigente el patrón industrial y el modelo de Industrialización por Sustitución de Importaciones (ISI), y en todo el resto de los países del mundo se mantenía efectiva parte importante de la política -de inspiración principalmente keynesiana- de la posguerra, en Chile, la crisis del patrón industrial -unido al muy particular desenvolvimiento que tuvieron allí la lucha de clases- permitió que se dejaran ver los primeros intentos de formación de un Estado neoliberal. En busca de un nuevo proyecto de desarrollo capitalista, el país se prestó como laboratorio de ensayo a nivel mundial de esta nueva política.

mundial en un momento dado y las políticas que predominantemente aplican los estados. Samir Amin, Crítica de nuestro tiempo. A los ciento cincuenta años del Manifiesto comunista, México, Siglo XXI, 2001.

24 Marini, “Proceso y tendencias...", Op Cit, p. 65

25 Alonso Aguilar, Globalización y Capitalismo, México, Plaza y Janés,2002

${ }_{26}$ Algunos de los aspectos planteados en este apartado para el caso de Chile, ya fueron abordados o bien en Pablo Cuevas, "La crisis del patrón de legitimidad del Estado neoliberal chileno", en Argumentos, núm. 86, enero-abril, 2018, pp. 131-149; o en: Pablo Cuevas y Teresa Rojas, "El proceso neoliberal chileno a cuatro décadas del Golpe”, en Estudios Latinoamericanos, nueva época, núm. 34, 2014, 75-94 
La transición hacia el nuevo patrón comienza con el golpe militar en Chile en 1973, pero las características del nuevo patrón se anclan en el desarrollo y contradicciones del ciclo del capital del patrón industrial, las cuales no eran exclusivas de Chile.

Suele interpretarse a la dictadura chilena y su implementación del neoliberalismo como una reacción en contra de una crisis económica y política profunda creada por el gobierno de la Unidad Popular. Más allá de ser este último el único caso histórico en que un gobierno electo mediante mecanismos institucionales democráticos se planteara reformas que condujeran a un tránsito desde el capitalismo al socialismo -lo que obviamente podría explicar por si sólo la caída de ese orden institucional burgués- sería impreciso juzgar que la única contrarrevolución capitalista posible en ese contexto fuera la implementación de un Estado neoliberal. Al comenzar el gobierno de Salvador Allende en 1970, el patrón industrial chileno ya mostraba evidentes fisuras, síntomas de una crisis profunda en la reproducción local del capital, lo que se une a una crisis del sistema de dominación y de los acuerdos de clases, que entraban en contradicción con los requerimientos del capital. En efecto, y como bien lo explica Marini ${ }^{27}$, es precisamente por ello, y por las luchas intraburguesas que se generaron en ese contexto, que fue posible la elección democrática de ese gobierno.

El proceso de cambio del patrón de reproducción del capital en Chile respondió a una crisis interna, aunque sin duda en diálogo con -y parte de- la crisis mundial capitalista, pero con elementos particulares claros; se trata de una crisis de agotamiento del patrón de reproducción del capital industrial, y además de la ineficacia del modelo de desarrollo ISI para continuar facilitando esa modalidad específica de reproducción del capital; ${ }^{28}$ una crisis de los acuerdos de clase y en las relaciones intra-burguesas, que se tensionaron ante las propias contradicciones de ese proyecto modernizador; una crisis del sistema de dominación, y finalmente, luego de 1970, con el gobierno de la Unidad Popular (UP), una crisis político-institucional, derivada de la inconsistencia entre el poder real en la sociedad, cristalizado en el Estado, y una administración de parte del aparato Estado que pretendía hacer una revolución desde allí, controlando sólo la dimensión formal institucional del poder ejecutivo en el aparato Estado. ${ }^{29}$

En Chile, a fines de la década de 1960, el sistema de dominación burgués se encontraba poderosamente erosionado, y la clase dominante mantenía fuertes diferencias. Desde la década de 1960 existía un cambio estructural en la industria, ${ }^{30}$ lo que genera una dinámica de división

\footnotetext{
27 Ruy Mauro Marini, El reformismo y la contrarrevolución: Estudios sobre Chile, México, Era,1976.

${ }^{28}$ Las claras limitaciones de la ISI en Chile para continuar promoviendo un crecimiento económico aceptable, desde la segunda mitad de la década de 1960, han sido señaladas por múltiples autores de diferentes corrientes teóricas y políticas. Ver por ejemplo el libro de Patricio Meller, Un Siglo de Economía Política Chilena (1890-1990), Santiago, Andrés Bello, 1998.

29 Pablo Cuevas y Teresa Rojas, op.cit.

30 Ese cambio implicaba un desplazamiento del eje de la acumulación de capital desde las industrias tradicionales textiles, vestido, calzado, etcétera- (donde predominaba la mediana y la pequeña burguesía) hacia industrias dedicadas a la producción de bienes más sofisticados y suntuarios para tales condiciones (industria automotriz y electrodomésticos), en donde predominaba el gran capital nacional y extranjero. Según destaca Olave, "Los cambios en la estructura productiva chilena de 1967 a 1970 hicieron posible el fortalecimiento de una fracción de la burguesía industrial ligada a ramas más complejas y al capital financiero" Patricia Olave, El proyecto neoliberal en Chile y la construcción de una nueva economía, México, IIEc-UNAM - El Caballito, 1997, p. 50. Esta fracción sostenía diferencias importantes con la pequeña burguesía respecto de cómo llevar la política económica y enfrentar la crisis, que cerraron la posibilidad de acuerdos políticos. Por ejemplo, "El sector emergente del gran capital ligado al modelo de especialización exportadora, presionaba por cambios más rápidos y drásticos, sobre todo en materia de control de inflación" Olave, Ibid, p.52. "Por otro lado, el sector tradicional pugnaba por que se diera de manera más "gradual" el
} 
en la burguesía, separando los intereses de la pequeña y mediana burguesía, de los intereses del gran capital. Además de ello, la agricultura también se encontraba en crisis -la necesidad de importación de alimentos derivada de esta situación generaba déficit a nivel macro- y la Reforma Agraria comenzada en 1962 no había logrado aumentar significativamente la producción, y por el contrario, había creado un ambiente muy contencioso en el medio rural, enfrentado los intereses de los sectores conservadores ligados a las haciendas con los de los sectores pequeñoburgueses modernizadores que habían impulsado dicho proceso. El ambiente de división de la burguesía favorece en Chile la elección de Salvador Allende y con ello, la llegada de un gobierno que pretendería hacer una revolución socialista desde la institucionalidad liberal. 31

En México, por su parte, si bien existió una reestructuración del patrón industrial en el mismo sentido que en Chile (orientándose igualmente hacia el gran capital, y este en bienes suntuarios) la división al interior de la burguesía fue menor y no se manifestó en un quiebre y una ruptura tan profunda como en Chile, dadas las características diferentes de esa clase y las relaciones entre sus sectores y representantes, mediadas por otro tipo de sistema político. Al respecto, antes que el sistema político que vehiculiza las tensiones estructurales, pensamos que lo central es que la contradicción entre los intereses de estos sectores de clase es menor en México que en Chile: el hecho de contar con un mercado interno varias veces el de Chile, tornó comparativamente menos contradictorios los efectos de este cambio estructural entre los intereses de diferentes sectores del capital. Un mercado interno más grande permitía una mayor tasa de crecimiento, y con ello, que grandes capitales mantuvieran intereses en el mercado de bienes salarios, y consecuentemente que el tamaño del mercado para bienes suntuarios aceptara mayores márgenes crecimiento. A partir de datos del Banco Mundial, podemos señalar que, durante la década de 1960, el crecimiento promedio anual del PIB fue de 4.3\% en Chile y 6.8\% en México. Esa tenencia continúa en la siguiente década, como el mismo indicador promedia 3.1\% en Chile y 6.7\% en México (más del doble). Sin embargo, ello no significa que en México no existiera una confrontación intraburguesa. El sexenio de Luis Echeverría (1979 - 1976) se caracterizó por una profundización del estatismo. La respuesta estatal a la crisis del patrón industrial durante la década de 1970 fue potenciar el modelo keynesiano, siendo ello muy claro particularmente desde 1974, cuando la presencia del Estado en la economía aumenta enérgicamente, paralelo al incremento de los recursos petroleros. Ello le valió al gobierno de Echeverría una relación tensa con determinados sectores del empresariado (capital financiero, gran capital y capital ligado al capital extranjero) que desde ese momento comenzaban a presionar cada vez más por una política neoliberal. Al interior del propio partido de gobierno, esa tensión se reflejó durante la década en la existencia de dos alas muy definidas, una keynesiana y otra monetarista.

Por otra parte, en Chile, durante el patrón industrial, la pequeña burguesía logra mantener su posición sin que sus representantes se transformasen en alta burguesía, que es lo que, de acuerdo a Marini ${ }^{32}$ ocurre realmente en México. En Chile, de esta manera, la pequeña burguesía conforma “...una verdadera capa política dirigente, que respondiendo a los intereses de su clase, convierte a ésta en su conjunto en una clase de apoyo activa al sistema de

control inflacionario. Este sector reconocía la necesidad de disminuir el gasto fiscal, pero dentro de un margen que no afectara el crecimiento económico." Olave, Ibid, p.53

31 El hecho de que los partidos pequeñoburgueses no se aliaran con la derecha conservadora para evitar el triunfo de Allende, muestra que dicho quiebre era realmente profundo.

32 Marini, El reformismo... Op Cit 
dominación vigente"33. En México, por su parte, existe un sistema de intereses corporativizados al interior del Estado, que incluye a sectores variados de distintas clases, pero que gira en torno a los intereses de los sectores hegemónicos. Las diferencias entre sectores solían saldarse al interior del régimen de partido único, mediante la alternancia de grupos o "alas" políticas en el poder, logrando de esa manera un cierto equilibrio. Estas alas podían incluir intereses de sectores de clase diferentes. Esta diferencia genera que la forma en que se enfrenta una crisis del patrón de reproducción de capital sea tan diferente en uno y otro país, y que en México esta confrontación no provoque un golpe de Estado, como sucede en Chile y otros países del cono sur.

En Chile, debe sumarse al contexto de división de la burguesía, que el triunfo de la UP condensaba sobre sí un largo proceso de organización de la clase trabajadora, de luchas y conquistas políticas y sociales, que ahora y con más fuerza comenzaba a poner en tela de juicio la propiedad privada y amenazaba a quienes tenían realmente el poder social con destruir su posición utilizando la vía institucional, ampliamente legitimada. ${ }^{34}$ Por lo tanto, a la división al interior de la burguesía, debe sumarse su confrontación directa con la clase trabajadora, que logra ocupar el gobierno sin aliarse con sectores del centro político. Por su parte, en México, los sectores trabajadores no evidenciaron el mismo proceso. Fueron más bien variablemente agregados en el sistema corporativo, pero carecieron de una organización de clase fuerte y autónoma de los intereses del partido de gobierno. Los sectores que supuestamente los representaban en el poder no pondrían en tela de juicio nada más allá de lo que ya había sido el juego de fuerzas al interior del partido oficial desde después del Cardenismo. Por lo mismo, el proceso de transición a una nueva política neoliberal sería más bien una lucha entre cúpulas.

En Chile, la división de la burguesía debilitó su frente común y posibilitó que la clase trabajadora llegara al control del ejecutivo del aparato Estado. El resultado no se hizo esperar, y el poder social que la burguesía realmente nunca perdió se manifestó violentamente "de golpe" en 1973, arrasando con ese gobierno popular, teniendo claro que la "restauración del orden" implicaba una respuesta en favor de una clase -una suerte de recuperación su poderpero sin la misma claridad respecto a cuál sería el proyecto específico mediante el cual se haría esa restauración, debido al vacío que dejaba la incredulidad de los representantes del gran capital respecto de las posibilidades de la ISI de conducir "el desarrollo". Ello ocurre en un país pequeño, con un mercado interno igualmente pequeño, donde ese tipo de política no había obtenido los resultados de países más grandes de la región, como México, Argentina y Brasil.

Por su parte, la confrontación por un cambio de modelo en México careció de esta respuesta violenta de parte de la élite que vemos en Chile, en parte, porque careció también del nivel de la confrontación de clases que tuvo ese proceso en el país sudamericano. En efecto, en México, la confrontación es directamente una discusión respecto del tipo de política económica, donde unos sectores del empresariado comienzan, por esos años, a exigir una orientación más pro-mercado, mientras en Chile, se trata de una lucha entre clases que destruyó al Estado vigente durante el patrón industrial, lo que permitió, en segunda instancia, replantear la política hacia una neoliberal.

\footnotetext{
33 Marini, Ibid, p.102

${ }^{34}$ La Unidad Popular constituye el fin de un ciclo de movilización social que se desarrolló a través de todo el patrón industrial. Al respecto puede consultarse a Luis Thielemann, "Movimientos obreros y movimientos sociales populares en Chile", en Iván Jaksic, Juan Ossa (editores), Historia política de Chile, 1910-2010, tomo I, Prácticas políticas, Santiago de Chile, FCE-UAI, 2017
} 
En cierta media, el gobierno de la UP tuvo la capacidad-efecto de unificar los intereses de todos los sectores de la burguesía, antes en conflicto, frente a un enemigo común. Quizás lo hizo poniendo a prueba aquello que Wright Mills ${ }^{35}$ denominara como el "acuerdo fundamental" de una élite. Éste acuerdo, en el caso de la burguesía chilena, consistía en la conservación de su posición como clase dominante, que dependía de la existencia de la propiedad privada, cuestión para ellos tan básica y "fundamental" que la Unidad Popular parecía poner en tela de juicio. El gobierno socialista no fue capaz de despojar de su poder real a la burguesía, por lo que ésta recuperó su posición apenas formalmente cuestionada mediante el uso de su fuerza. Esto explica, por ejemplo, el conocido apoyo del partido Demócrata Cristiano -representante por entonces de la pequeña burguesía- al golpe de Estado. Luego se decidiría cuál sería el proyecto burgués específico, en lo próximo, lo urgente era eliminar aquello que arriesgaba lo que el "acuerdo fundamental" protegía. ${ }^{36}$

Ante ese "vacío" que sucede al golpe militar chileno aparece la propuesta neoliberal como aquella defendida por un sector de la burguesía -que ahora se tornaba en el dominantepropuesta que previamente había tomado la forma de documento al ser planteada como el programa de gobierno del candidato Jorge Alessandri en 1970. Debe notarse que, previo al gobierno de la Unidad Popular, la reproducción del gran capital ya reclamaba una política más favorable a su sector, la cual se materializaba en un programa de gobierno concreto. Dicho texto -El Ladrillo37- redactado por profesores de economía de la Universidad Católica, cristaliza en buena medida la propuesta de la corriente económica monetarista, y se transforma luego de 1975 en el programa de gobierno de la dictadura. Ese documento es el origen del llamado modelo neoliberal chileno. 38

\footnotetext{
35Charles Wright Mills, La élite del Poder, México, Fondo de Cultura Económica, 1956

36 Pablo Cuevas y Teresa Rojas, Op.Cit.

37 CEP varios autores, El ladrillo. Bases de la política económica del gobierno militar chileno, Santiago de Chile, CEP, 1992.

38 Algunos historiadores como Manuel Gárate han criticado la idea de que “(...) las Fuerzas Armadas fueron principalmente un 'instrumento de clase' en manos de los civiles que buscaban la caída del gobierno de la Unidad Popular y el fin del modelo de Estado de Compromiso o Benefactor" (Manuel Gárate, La revolución capitalista en Chile (1973-2003), Santiago, Ediciones Universidad Alberto Hurtado, 2012, p.181). Para éste autor, la lucha al interior de la junta por la búsqueda de una estrategia de desarrollo (nacionalistas versus neoliberales) implicaría que esta "instrumentalización" de los militares no sería efectiva, otorgándoles a las decisiones individuales y luchas entre los propios mandos de las Fuerzas Armadas la capacidad de definir e imponer un proyecto de esta naturaleza. Gárate argumenta que los militares se habrían hallado más cerca del nacionalismo desarrollista que del neoliberalismo, sin embargo, la "(...) falta de proyecto de Pinochet y su necesidad de afirmarse en el poder y legitimarse, fue lo que lo incitó a buscar un proyecto propio, revolucionario y fundacional” (Ibid, p.182). De esta manera, para Gárate, al igual que para otros autores como Patricio Meller (Op.Cit.) es el criterio de los militares, sus voluntades y preferencias el factor decisivo de la imposición de un modelo de desarrollo. Señala el autor: "Creemos que los militares que salieron vencedores de esta pugna se sintieron atraídos por la nueva ortodoxia económica, no tanto porque comprendieran su racionalidad interna, sino porque les ofrecía coherencia y disciplina dentro de un marco técnico-científico y, por lo tanto, ideológicamente neutral y alejado de toda negociación y arreglo político.” (Gárate, Op. Cit., p.195). Al respecto, nuestra postura es opuesta. Si bien es cierto que existía una pugna por continuar con un modelo nacionalista o reemplazarlo por algo diferente, al interior de los mandos militares, ello no es sino la expresión de las tensiones que se habían generado entre los dos sectores de la burguesía que representaban a cada opción, como se explicó más atrás. Como bien reconoce Gárate, la alianza entre estos sectores estaba provocada sólo por el rechazo al proyecto revolucionario de la Unidad Popular. Sin embargo, este autor olvida analizar la base de apoyo empresarial del Golpe, sus conflictos e intereses concretos y omite relacionar esto con los sectores que habían ganado mayor poder económico en el ciclo final del patrón industrial, y otros pormenores no tan irrelevantes como los intereses norteamericanos. Esto se debe, posiblemente, al sesgo politicista o determinismo político que el propio autor reafirma a lo largo de su obra, que le impide ver las condiciones que pueda imponer el aparato productivo. Al
} 
Mientras en México apenas comenzaban a ganar espacio al interior de la élite las propuestas neoliberales y el gobierno intensificaba su política keynesiana, en Chile, de forma muy precoz, comenzaba un experimento neoliberal sin precedente mundial. Como han destacado varios connotados autores, “...el primer experimento de formación de un Estado neoliberal se produjo en Chile, tras el golpe de Pinochet..."39. Inmediatamente después de su violenta llegada al poder, el gobierno militar realizó transformaciones profundas en la estructura económica y social del país. Para reactivar la economía chilena, la dictadura convocó a un grupo de economistas conocidos como los "Chicago Boys", dada su adscripción a las teorías de Milton Friedman, que entonces ensañaba en Chicago. 40

Ffrench-Davis ${ }^{41}$ también destaca la singularidad del proceso chileno, señalando que éste es el principal caso de aplicación moderna de la ortodoxia monetaria, por su pureza, profundidad y extensión de su cobertura; su prolongada vigencia (1973-1982, en la etapa más ultra-liberal); y la publicidad mundial que recibió como un caso de éxito del modelo. Harvey, por su parte, posiciona a este caso como el precedente mundial, como el experimento de la Universidad de Chicago para demostrar la validez de sus teorías. ${ }^{42}$

En este nuevo proyecto, el gran capital, en sus diferentes fracciones, impone sus condiciones, en alianza con el capital extranjero. Articulado con las readecuaciones que comienzan a tener lugar en el sistema mundial, el nuevo proyecto modernizador supuso la eliminación de los "acuerdos de clase" que constreñían las ganancias del capital, y la eliminación de las restricciones que dificultaban que la producción tuviera por mercado "todo el mundo", desvinculando el salario del consumo. En resumidas cuentas, se trataba en muchos sentidos de un proyecto de retorno al "liberalismo" decimonónico.

Por su parte, de manera similar a lo que ocurre en Chile con El Ladrillo, que "esperaba su momento" luego del golpe, en México, igualmente la visión que luego se denominará como "neoliberal" estará presente de manera previa a su aplicación, "esperando su momento" luego de la crisis de la deuda en 1982.43 Entre 1974 y 1982, mientras Echeverría y José López Portillo intensifican el modelo ISI, comienza un periodo de discusión y asenso de las ideas neoliberales: los grandes empresarios y sus representantes rompen paulatinamente con el keynesianismo. Al iniciar el gobierno de López Portillo, los ideólogos de los empresarios ya denotaban una

respecto nuestra hipótesis sería más bien que pese a que los militares eran más proclives a un modelo nacionalista desarrollista, los intereses del sector del gran capital, capital financiero, capitales asociados al capital extranjero, grandes capitales asociados al poder tradicional latifundista, fueron capaces de imponer dentro de la junta sus intereses. El cambio en el patrón de reproducción de capital es un proyecto de clase colectivo, donde se juegan los intereses de aquellos sectores que más poder concentran, no es el resultado de las preferencias personales de uno u otro individuo o cargo militar, por más poder formal que se le invista.

${ }^{39}$ Harvey, Breve historia... Op Cit, p. 14

40 Estos economistas eran el producto de un programa estadunidense de formación de posgrado de economistas chilenos de la Universidad Católica y Universidad de Chile en Chicago.

${ }^{41}$ Ricardo Ffrench-Davis, Entre el neoliberalismo y el crecimiento con equidad; tres décadas de política económica en Chile, Buenos Aires, Siglo XXI editores, 2004.

42 En sus palabras, todo el proceso: “...sirvió para proporcionar una demostración útil para apoyar el subsiguiente giro hacia el neoliberalismo tanto en Gran Bretaña (bajo el gobierno de Thatcher) como en Estados Unidos (bajo el gobierno de Reagan) en la década de 1980." Harvey, Breve historia... Op Cit, p. 15

43 En efecto, en dicho país estas ideas estuvieron activas a lo largo de todo el patrón industrial, encarnadas en un grupo de intelectuales y empresarios relacionados a la Mont Pelerin Society, quienes incluso formaban economistas dentro de esas líneas teóricas, sosteniendo contactos y visitas de importantes representantes de la denominada escuela austriaca, como Ludwig von Mises y Friedrich von Hayek. Ver: Ma. Eugenia Romero, "Las raíces de la ortodoxia en México", en: Economía UNAM, nº 24, p.20-50 
retórica neoliberal, reclamando una menor presencia del Estado en la economía, en una línea opuesta y en confrontación con la línea del gobierno, que impulsaba una política de expansión del gasto, ampliación de las empresas públicas e incremento de la protección. Esta tensión entre estatistas y liberales es clara al interior del propio partido de Estado y se manifiesta al interior del gabinete de López Portillo.

Fueron los recursos petroleros los que permitieron a Echeverría y Lopez Portillo, en principio, financiar esta política de expansión del gasto. El Estado mexicano contrajo importantes deudas durante la década para realizar inversiones petroleras. La exportación de crudo se constituyó en una importante fuente de divisas y sostén de un nuevo impulso del desarrollismo mexicano a fines de la década de 1970. Entre 1978 y 1981 el crecimiento promedio anual de la economía mexicana alcanzó el 8\%. Todos los sectores de la economía se encontraban en pleno empuje debido a la fuerte inversión del gobierno, a su vez soportado en el incremento de la deuda pública y privada, supuestamente garantizada por la amplia disponibilidad de petróleo. ${ }^{44}$ Ello permitió una mejora en las condiciones salariales y reforzó las redes corporativas del gobierno con los sindicatos. Sin embargo, en 1979 las tasas de interés comienzan a subir, y en 1981 se produce una caída importante en los precios del petróleo. Los acuerdos previos con la cúpula empresarial impidieron que la política desarrollista pudiera ser financiada por la vía de una reforma fiscal que aumentara la recaudación tributaria, lo cual no fue problema mientras había recursos financieros baratos en el mercado internacional, pero si lo fue cuando ese contexto cambió al finalizar la década.

En fuerte contraste con esta arremetida de la política keynesiana en México, en Chile, la segunda mitad de la década de 1970 estuvo marcada por la aplicación inédita del neoliberalismo. Es factible distinguir dos fases en la aplicación de las estas reformas estructurales en Chile, una primera, que va de 1974 a 1982-1983, con características más extremas -más ideológicas si se prefiere- y una más pragmática luego de la crisis de la deuda, desde 1982, en la cual la ideología dominante en la primera etapa subsiste con arreglos al margen ${ }^{45}$. En la primera etapa las transformaciones económicas se localizaron en los campos fiscal,46 financiero, laboral, relaciones económicas con el exterior, y propiedad pública. Luego se llevaría adelante una profunda reforma previsional. En general, el campo de acción económica del Estado se restringió fuertemente en todas estas áreas. Por su parte, las

\footnotetext{
44 Juan Pablo Arrollo, “Fundamentos y génesis de la política económica del Estado neoliberal en México, 1980-2010”, en Ma. Eugenia Romero Sotelo (coord.), Fundamentos de política económica en México, 1910-2010, México, Facultad de Economía- UNAM - Colegio Nacional de Economistas, p. 427-526

45 Ffrench-Davis, op. Cit., y Olave, Op. Cit.

${ }^{46}$ La política fiscal sufrió modificaciones importantes. La reforma tributaria fue la primera medida. Se eliminó el impuesto a las ganancias del capital y al patrimonio. Se pretendía lograr una carga tributaria "neutra", que no "distorsionara" la asignación de recursos que "perfectamente" haría el mercado En la misma línea, otra política fue la reducción del gasto público de todo tipo; se privatizaron los bancos -estatizados en el por la Unidad Popular- se liberalizaron las tasas de interés, se desreguló el crédito y se autorizó el establecimiento de nuevas casas financieras, con muy pocas limitaciones; y se fijó una tasa de cambio única en 1975 Por otro lado, se eliminó prácticamente la totalidad de las restricciones arancelarias y todo tipo de mecanismo de control de precios; se privatizaron las empresas del Estado, tanto las expropiadas durante el gobierno anterior, como aquellas creadas por el Estado durante la etapa del patrón industrial. En 1980, se privatizó el sistema previsional. A todo lo anterior se suman las reformas en el plano social, tendientes a la creación de "una sociedad competitiva de hombres libres" lo que supuso cambios en el sistema universitario y escolar, en las prestaciones de salud, colegios profesionales, organizaciones estudiantiles y -con una importancia gravitante para el modelo- en los sindicatos, lo que disminuyó el poder de negociación del trabajo sobre el salario e influyó en la caída de los salarios reales. Ffrench-Davis, op. cit.
} 
transformaciones sociales, pasaron por el disciplinamiento del mundo del trabajo de la sociedad civil al nuevo orden impuesto. 47

Se intentaba imponer una "sociedad competitiva de hombres libres", que se inspira en una "utopía" en la que la llamada "mercantilización de todas las cosas" se concretara, llevando la lógica del mercado a todos los planos de la sociedad, donde dicha institución es el medio y el lugar donde los seres humanos interactúan "libres" unos con otros. 48

\section{La crisis de la deuda: un parteaguas en Chile y México}

Tanto en Chile como en México, la crisis de la deuda Marca un cambio de etapa. Mientras para México constituye el fin definitivo del modelo industrializador, en Chile obliga a la aplicación de un neoliberalismo más moderado en cuanto a la radicalidad de sus políticas económicas.

En Chile, el efecto de la crisis de la deuda, originada en México, representa un parteaguas en la realización de una utopía ultra-liberal. En respuesta a la crisis la dictadura debió ajustar sus políticas para enfrentar la severa restricción externa y estimular la recuperación interna. Comienza desde esos años una nueva etapa, más pragmática, que supuso la reversión y reconsideración de algunas de las primeras reformas.

Por su parte, en México -epicentro de esta convulsión- la crisis de la deuda es el resultado de la combinación de la política de expansión del gasto del gobierno de López Portillo, con los fuertes cambios ocurridos en el entorno financiero internacional. La enorme deuda pública y privada del país es determinante en el hecho de que, al momento de subir las tasas de interés y bajar los precios del petróleo, los compromisos contratados a tasas variables se hayan tornado impagables para la economía mexicana. Esta crisis inclina la balanza política hacia aquellos sectores al interior del partido de gobierno, que durante toda la década anterior demandaban una política fiscal más "ordenada" y que cuestionaban la expansión del gasto y el crecimiento del Estado. Serían ellos, entonces, los encargados de conducir la recuperación. De esta manera, luego de una importante fuga de capitales a fines de 1981 y de la estatización de la Banca, López Portillo entrega el gobierno a un representante del ala neoliberal del partido de gobierno, Miguel de la Madrid, elegido candidato por su propio predecesor, como era la tradición en el Partido Revolucionario Institucional (PRI). Según las memorias de López Portillo, tomó esta decisión porque creía que en el contexto de crisis era necesario un presidente que estuviera próximo al sector financiero. ${ }^{49}$

Sin debate alguno, sin mediar discusión previa en la sociedad mexicana, el programa de gobierno de Miguel de la Madrid será el programa de ajuste monetarista. Pese a la ausencia de

\footnotetext{
47 Olave lo señala de la siguiente manera: "El disciplinamiento de la sociedad civil y, en especial, del mercado laboral -a partir del estado de excepción que se inaugura en septiembre de 1973- constituyen una base de estabilidad social impuesta que ha permitido incrementar la rentabilidad del capital, así como transferir ingresos desde los sectores asalariados hasta la acumulación de capital." Olave, Op. Cit. p. 194

48 Como bien lo señala Garretón, el modelo cultural de esta refundación societal comprende una visión negativa del proceso de las décadas precedentes. El sistema político y la creciente preeminencia de lo estatal, serían las causas centrales del estancamiento económico (falta de libertad individual colapsada por un Estado que la ahoga). Se reivindica la propiedad privada como único fundamento de la libertad política, y ello debe quedar garantizado por el predominio de las leyes de mercado en todas las esferas de la vida nacional. M. Antonio Garretón, El proceso político chileno, Santiago de Chile, FLACSO, 1984.

${ }^{49}$ José López Portillo, Mis tiempos: biografía y testimonio, México, Fernández Editores, 1998.
} 
violencia política en el caso mexicano, en este punto el proceso no difiere sustancialmente del encabezado por Pinochet en Chile. La diferencia es que en "...México se impulsó desde arriba, mediante un acuerdo estratégico entre el gran capital (nacional y extranjero) y el Estado corporativo, sin necesidad de que lo antecediera un golpe militar..."50 mientras que en Chile fue necesario, desde el punto de vista de la burguesía, una contrarrevolución y retomar el control de la totalidad del Estado.

La primera medida del gobierno de Miguel de la Madrid fue la aplicación del Programa Inmediato de Reorganización Económica (PIRE) cuyo propósito principal era eliminar las presiones inflacionarias, reduciendo la demanda y el salario real, mediante una nueva política cambiaria -que devaluó fuertemente la moneda- y una política monetaria que restringió la liquidez. ${ }^{51}$

Sin embargo, más allá de que en México internamente ya estaban resueltos los intereses internos en función del ajuste -lo que implicaba cambiar profundamente no sólo la economía sino también los equilibrios de poder al interior de la sociedad mexicana y su ordenamiento corporativo- existió también un condicionamiento externo respecto de la forma en que debía conducirse la salida de la crisis, pues, el Fondo Monetario Internacional (FMI) exigió la política de ajuste fiscal para renegociar la deuda.

El escenario financiero internacional se había reconfigurado durante la década de 1970, y como consecuencia, el orden institucional internacional en la década de 1980 presionaba por expandir una política neoliberal. Desde el quiebre del acuerdo de Breton Woods en 1971 comienza una serie de transformaciones en las instituciones bancarias internacionales. En 1973 comienzan los cambios en los estatutos del FMI, los que se coronan en 1979, cuando en dichos cambios se establece la posibilidad de dicha institución de condicionar a los países deudores el apoyo financiero a prácticas económicas "adecuadas", "promoviendo" de esta manera el paso a sistemas de cambio flotante, obligando en la práctica a esos países a promover la estabilidad de su cambio mediante políticas "ordenadas". Ya a inicios de la década de 1980 todos los economistas keynesianos habían sido expulsados del FMI y el Banco Mundial (BM). En este plano, la crisis de acumulación había desencadenado una "guerra" al interior de estas instituciones, que a estas alturas los monetaristas ya habían ganado ampliamente, conquista que no era sino el reflejo del nuevo orden de fuerza de clases mundial a nivel global, y que se imponía ahora sobre los países deudores condicionados.

En este contexto, el FMI exige los programas de ajuste fiscal, a México y los demás países que buscaban re-pactar la deuda. Estos programas incluían, a muy grandes rasgos: reducir intervención estatal en la economía, la privatización de empresas públicas (reducción del Estado), apertura comercial y financiera, desregulación económica, entre otras medidas. Es muy claro y evidente que este paquete "técnico" de medidas llevaba implícito una opción política clara y una visión de la sociedad ajustadas a la utopía de la Mont Pelerin Society, sin embargo, su aplicación no se sometía, ni siquiera formalmente, a los mecanismos de deliberación democrática. Sin mayor oposición al interior del gobierno, con un sector proreformas en el poder, México firma en 1983 los compromisos necesarios para renegociar la deuda. Con ello, comienza a instalarse, paulatinamente, un modelo neoliberal en dicho país, proceso que, a diferencia del chileno, sería gradual. El ajuste económico mediante una mayor

\footnotetext{
50 Adrián Sotelo, México (re)cargado: Dependencia, neoliberalismo y crisis, México, FCPyS-UNAM - Itaca, 2014, p.67

51 Graciela Flores, Luisa Paré, Sergio Sarmiento, Las voces del campo. Movimiento campesino y política agraria, 1976 1984, México, IIS-UNAM - Siglo XXI, 1988
} 
austeridad fiscal fue la primera medida, se modifica la política cambiaria, devaluándose el peso mexicano en 1982 y 1983 . Además, se experimenta una disminución de la inversión pública y se incrementan los impuestos indirectos y las tarifas del sector público.

En 1983 comienza en México un periodo de constitucionalización del neoliberalismo, por medio de una serie de reformas a la carta magna, que posicionan al equilibrio fiscal como eje de la nueva institucionalidad económica, lo que a su vez da cuenta de la fuerte decisión de las élites locales de fijar el modelo e impedir el regreso a un modelo keynesiano. Esa decisión se verá reforzada por la firma del General Agreement on Tariffs and Trade (Acuerdo General sobre Aranceles Aduaneros y Comercio, GATT) en 1985 -que a su vez fija y compromete con el exterior la política de apertura comercial- y quedará confirmada cuando en 1985 se rompa la "tradición" al interior del PRI y el ala en el poder no alterne el gobierno con el ala opuesta. El nombramiento de Carlos Salinas de Gortari como candidato para suceder a Miguel de la Madrid confirma que el escenario de poder ha cambiado, y que la decisión de la burguesía mexicana no dará pie atrás. El antiguo sector keynesiano al interior del PRI es apartado del poder. Ello generará una ruptura política al interior de dicho partido y afianzará el proyecto neoliberal, aún en vías de implantación.

Es a partir del gobierno de Salinas de Gortari que se consolida en México una política neoliberal y que el patrón exportador de especialización productiva opera de manera clara. El inicio del Tratado de Libre Comercio de América del Norte (TLCAN) en 1994 es otro hito que viene a consolidar el nuevo modelo de desarrollo y que cristaliza a la economía mexicana como exportadora y vinculada a la cadena productiva estadounidense. En este sentido "...el sector exportador es el motor de la economía dependiente neoliberal de México, muy bien se puede dejar de lado el desarrollo endógeno del país, tanto a nivel de la producción como de los mercados dirigidos a las grandes masas populares cuyo poder de compra merma cada día más" 52 .

Por su parte, en Chile, el impacto de la crisis de la deuda es igualmente muy fuerte. Si bien ese país había incorporado de manera aún más extrema varias de las medidas de ajuste que exigía el FMI, había mantenido un sistema de tipos de cambio fijo, y se encontraba fuertemente endeudado. A ello se le suma el efecto destructivo sobre una buena parte del sector productivo que tuvo el neoliberalismo extremo de la década de 1970. Cuando en 1981 el Estado intervino la banca y los indicadores económicos se tornaron desastrosos se hablaba en Chile de un fracaso neoliberal. 53

Luego de esta crisis, en Chile lo prioritario fue generar un superávit comercial, a fin de servir la deuda externa. Para ello se redujeron las importaciones y se promovieron las exportaciones, lo que se hizo mediante: un aumento del arancel uniforme; el uso de una batería de instrumentos para estimular las exportaciones; y una política cambiaria destinada a fortalecer la competitividad externa de la economía chilena y la capacidad de generar divisas.

En síntesis, neoliberalismo enfrentará la crisis del patrón industrial mediante una política que ayudará al capital a transformar su patrón de reproducción. El nuevo modelo, en

\footnotetext{
52 Sotelo, op.cit., p.195

53 En 1985 Zapata escribía: "Cuando a fines de 1981 el gobierno tuvo que intervenir el aparato financiero, anticipándose a una insolvencia del mismo, se sintió la señal de que algo andaba mal en la puesta en práctica del modelo de los Chicago Boys. Varios bancos pasaron a ser administrados por la Superintendencia de Bancos y Compañías de Seguro, con lo cual el mito del Estado liberal no interventor se vino al suelo." Francisco Zapata, "Crisis económica y movilización social en Chile (1981-1984)",en Foro Internacional, Vol. 26, No. 2 (102), p. 215
} 
ambos países, se basó en la penetración del capital extranjero y en la concentración del ingreso, lo que permitiría una mayor inversión y con ello, una nueva etapa de acumulación.

En Chile, además, el proyecto de clase neoliberal contempla una desarticulación social iniciada por el golpe militar, vía la fragmentación sindical, la segmentación de los procesos productivos y la ruptura de los vínculos sociales -base de las reformas privatizadoras de los sistemas de pensiones, salud y educación- para promover el individualismo y las políticas focalizadas. El resultado no es sólo una sociedad sin capacidad de respuesta, sino además un "impulso económico", debido a unos trabajadores bien disciplinados por el capital.

Durante la década de los noventa, en ambos países, se experimentan procesos instauración de regímenes de democracia procedimental. El llamado retorno a la democracia en Chile y el fin del sistema de partido único en México no cambiaron en nada el carácter del nuevo modelo económico y el patrón de reproducción de capital en estos países. Por el contrario, parece haber sido necesario políticamente legitimar estos cambios mediante estas transformaciones. Ni los gobiernos de la Concertación de Partidos por la Democracia en Chile, ni los dos gobiernos del PAN en México modificaron el modelo, por el contrario, en algunos aspectos lo profundizaron, pero ahora con "autoridad" democrática. Más allá de que en ambos casos es muy discutible el carácter democrático procedimental de esos procesos posteriores a la aplicación del neoliberalismo, (en Chile porque dicha democracia opera dentro de las reglas del juego impuestas por la dictadura y entregó cuotas de poder desproporcionadas a los sectores conservadores y en México porque se duda de un desempeño transparente de los procesos eleccionarios) pareciera ser que este tipo de democracia obedece a un nuevo patrón de legitimidad que caracterizan a las relaciones mando/obediencia en la región en esta etapa. Jaime Osorio ${ }^{54}$ plantea que ante el vacío de legitimidad dejado por los estados de bienestar y acuerdos de clase que incluían sectores más amplios de la sociedad, se impone esta democracia como mecanismo de legitimidad. "La legitimidad se alcanzaría ahora no por las prebendas estatales otorgadas a sujetos acostumbrados a pedir y esperar, sino a adultos políticos que conocen y deciden en consultas electorales transparentes y que reciben desde el mercado los beneficios equivalentes a su esfuerzo y capacidad." 55

En efecto, en Chile, como bien lo señalaba Pilar Vergara en 1984, apenas pasada la crisis de la deuda, "...la misión "salvadora" que el poder autoritario se había asignado, comienza a ser cuestionada por las propias fuerzas que habían constituido hasta entonces sus principales bases de apoyo" 56 . Luego de la crisis y de las readecuaciones al modelo, para las clases dominantes la misión del gobierno militar consiste ahora “...en conducir vigorosamente la transición hacia un orden democrático eficiente y estable.”57. En México, por su parte se enfatiza en un discurso que posiciona como un logro romper con los intereses de la vieja burguesía poco competitiva y los cacicazgos políticos del PRI para lograr la liberalización y democratización, y se planteaba explícitamente que "El éxito de la reforma económica requiere de una transición política sin grandes sobresaltos." 58

\footnotetext{
54 Jaime Osorio, Estado, biopoder y exclusión. Análisis desde la lógica del capital, Barcelona, Antropos - UAM-X, 2012.

55 Ibid, p.64

56 Pilar Vergara, Auge y caída del neoliberalismo en Chile: Estudio sobre la evolución ideológica del régimen Militar, Santiago de Chile, FLACSO, 1984, p.330

57 Idem.

58 Luis Rubio, “La reforma económica y el cambio político en México", en Riordan Roett, (comp.), La liberalización económica y política de México, México, Siglo XXI, p. 72
} 
A partir de estos procesos de “democratización” la transición hacia el modelo neoliberal queda terminada en ambos países, asegurando la estabilidad del funcionamiento del nuevo patrón exportador. Ello no quiere decir que no existan modificaciones, pues, en algunos casos se siguen profundizando y en otros se suavizan algunas tendencias más radicales. Pese a ello, en lo estructural, el nuevo modelo económico que facilita un nuevo patrón del capital para transitar por su ciclo ya se encuentra instalado, con solidez y legitimidad, en la primera mitad de la década de 1990.

\section{Conclusión: lo general y lo particular en estos procesos}

Para referir a los elementos comunes entre los procesos de cambio de patrón de reproducción de capital, lo primero es señalar que Chile y México comparten algo más allá que la pertenencia a una región con lazos socio históricos y culturales comunes: este es su condición de países dependientes. ${ }^{59}$ Esto significa que ambos países se encuentran insertos en estructuras que generan para cada uno de ellos requerimientos similares en la reproducción del capital. Tanto las razones detrás de la instauración de modelos industrializadores en la posguerra, como las de su crisis, son comunes en muchas economías dependientes. De manera similar, las nuevas necesidades de reproducción del capital serán similares y, por tanto, los proyectos hegemónicos también lo serán. Por lo tanto, la necesidad de una política neoliberal es común. Ahora bien, ello es tanto un requerimiento externo como interno. Es externo, porque la lógica misma de la reproducción del capital es dependiente y subordinada al capital internacional, y éste tiene intereses específicos en las economías dependientes. Y es interna porque esa estructura genera, al interior de cada país, sectores del capital que comparten los intereses del capital internacional.

Sin embargo, en lo concreto, estos requerimientos se expresarán en situaciones y contextos disímiles, que generan las diferencias que hemos resaltado. Respecto a la forma que adoptan estos procesos en lo concreto, lo primero que llama la atención, tal como lo destacamos al principio, es el hecho de que en Chile la violencia de Estado fuera el elemento clave en la imposición del modelo económico, a diferencia de lo ocurrido en México. ${ }^{60}$ Nuestro examen

\footnotetext{
${ }^{59} \mathrm{Al}$ formar parte de América Latina, ambos países surgieron a su vida independiente participando de un mercado mundial con una fuerte de demanda de alimentos y materias primas. Ambos países desarrollan sus estructuras económicas y sociales en una relación de dependencia, "entendida como una relación de subordinación entre naciones formalmente independientes, en cuyo marco las relaciones de producción de las naciones subordinadas son modificadas o recreadas para asegurar la reproducción ampliada de la dependencia." Marini, Dialéctica... op.cit., p.18. Esta condición estructural común a la región latinoamericana genera que ambos países compartan históricamente patrones de reproducción de capital, cada uno con sus especificidades, pero con características estructurales generales. Históricamente, estos patrones cambian, de acuerdo a las fases del capitalismo, pero en todo momento, estos patrones de reproducción de capital son dependientes, y se caracterizan por un ciclo del capital que responde a las necesidades del capital internacional, entronizando esa dependencia en sus propias estructuras económicas y de clases, razón por la que la dependencia no es sólo una relación externa, sino una estructura interna 60 Debe destacarse que ello es específicamente en lo que respecta al cambio de modelo de desarrollo. En términos generales, la violencia política y de Estado ha sido comparativamente mayor en México que en Chile y ello es especialmente efectivo para el periodo de vigencia del Estado desarrollista que impulsaba el proyecto de industrialización. Sin embargo, ello no debe llevar a mostrar la violencia como un comportamiento excepcional del estado en Chile. Brian Loveman y Elizabeth Lira ("La violencia política en Chile: Contextos y prácticas desde 1810", en Iván Jaksic, Juan Ossa (editores), Historia política de Chile, 1910-2010, tomo I, prácticas políticas, Santiago de Chile, FCE-UAI, 2017) han hecho hincapié en que la violencia política, pese a que ha sido comparativamente menor que en los demás países latinoamericanos, varias de sus formas constituyen parte de un repertorio de utilización esporádica
} 
señala que la principal causa de esa diferencia es el distinto nivel de confrontación de clases al interior de ambos países, y los diferentes mecanismos para administrar ese conflicto. A su vez, estos conflictos de clases reconocen dos áreas diferentes: por un lado, el conflicto inter-burgués y por otro, el conflicto entre clases: los trabajadores y las burguesías. En un contexto de crisis donde los pactos de clases resultaban ser un lastre para la reproducción de capital, una diferente dinámica al respecto genera diferencias importantes. Al respecto puede anotarse, por un lado, una mayor organización de la clase trabajadora en Chile, capaz de movilizar un proyecto de Estado alternativo de carácter no burgués, por vía institucional, versus una clase trabajadora mayormente integrada en los estamentos corporativos del Estado mexicano, no sin excepciones partidarias e incluso guerrillas, pero que, en lo medular, no se encontraba en posición de organizar un proyecto fuera del existente que lograra realmente amenazar al hegemónico. Esto generará una relativa mayor confrontación de clase en Chile, pues, la crisis del patrón de reproducción de capital no sólo dejaba para el capital la necesidad de generar los cambios institucionales que permitieran facilitar el cambio de patrón, sino además dejaba un fortalecido enemigo, ya no sólo de la modalidad del capitalismo, sino del sistema mismo.

Por otro lado, y profundamente relacionado a lo anterior, la división al interior de la burguesía también fue mayor en Chile que México. Las causas de ello tienen fundamentalmente dos orígenes. El primero se encuentra en la reproducción misma del capital y la segunda en la dinámica histórica entre los sectores de clase y los mecanismos de administración de los conflictos. El distanciamiento entre los intereses de la pequeña burguesía y gran burguesía fue mayor en Chile porque, al contar este país con un mercado interno pequeño, el dinamismo industrial fue mucho menor, lo que generó un más rápido agotamiento de los límites del mercado los sectores productores de bienes salarios, y una mayor premura de los sectores productores de bienes suntuarios por estrategias exportadoras. La misma limitación estructural, impuesta no sólo por la menor población, sino por los bajos salarios, generó una mayor radicalidad en los sectores burgueses medios por modernizar estructuras en las que la vieja oligarquía -íntimamente relacionada con los sectores del gran capital y capital extranjerotenía intereses, como fue la reforma agraria. Modernizar el campo era visto por la pequeña y mediana burguesía chilena, como una estrategia que permitiría aumentar la producción agrícola, bajando la parte del salario que los trabajadores destinada a alimentación y dejando una mayor parte para el consumo de bienes industriales (plusvalía relativa). Esa estrategia desarrollista llevó a la pequeña burguesía chilena a radicalizar una reforma agraria que polarizó a esa clase, generando profundas diferencias entre el centro político burgués y la derecha tradicional. En México, por el contrario, la pequeña burguesía se encontraba menos distanciada de la gran burguesía. Los acuerdos de clase, se van rompiendo en Chile por el gran peso de las contradicciones del proceso de industrialización dependiente. En México, la situación es bien diferente. Si bien la destrucción de los acuerdos de clase de todos modos se vincula a las contradicciones del proceso, lo es de una manera más indirecta. La misma contracción que generaban los salarios bajos en el mercado se suplía mediante una inyección de recursos públicos, que no provenían del propio ciclo interno, sino del exterior. Ese esquema precipitó la crisis de la deuda cuya salida supuso la ruptura de esos acuerdos. En este sentido, la burguesía se mantuvo más unida en México, los sectores keynesianos no pretendían afectar de manera

pero recurrente a lo largo de toda historia republicana de Chile. En México, por su parte, la violencia estatal es especialmente recurrente entre las décadas de 1960 y 1980. Al respecto se puede consultar el libro de Verónica Oikión y María García, Movimientos armados en México, siglo XX, Zamora, El Colegio de Michoacán, 2007. 
tan frontal los intereses de los sectores del gran capital, como sí ocurrió en Chile. Si los recursos para sostener la política keynesiana en México hubieran provenido de una reforma tributaria, posiblemente se habría generado una mayor confrontación intra-burguesa, pero ello no ocurrió. Como consecuencia, no hubo una división tan polarizada de la burguesía que le permitiera a la clase trabajadora plantearse de manera efectiva con un proyecto de clase alternativo, y ello es al marguen de lo efectivo que había sido el Estado en: por un lado, lograr corporativizar a los trabajadores, limitando su organización por fuera de ese Estado, y por otro, combatir por la fuerza a la insurgencia rural y la protesta social urbana.

El patrón industrial en México logró un mayor desarrollo de la industria que en Chile y creó un Estado corporativo que logró un sistema de dominación mucho más efectivo que el chileno. Ello es relevante para comprender el surgimiento de un proyecto como la UP en Chile y no en México. El uso de la fuerza no fue necesario para imponer el nuevo proyecto en México -aunque lo haya sido para mantener el orden del Estado desarrollista- para ello la gran burguesía se valió de las lógicas de poder instituidas formal e informalmente, propias del propio Estado corporativo. Sin duda, ello no implica que el Estado Mexicano no operara mediante el uso de la violencia, la cual ha formado parte activa en su estrategia de control social desde antes de la revolución mexicana, sin embargo, no existe un requerimiento específico del uso de la fuerza para la concreción del proyecto neoliberal en específico. Al interior de la burguesía la quiebra fue, como hemos visto, menor respecto de Chile. En la medida que esta ruptura fue más moderada, el ritmo fue también diferente, lo que explica además lo más tardío y gradual del proceso mexicano respecto del chileno.

Fueron, la participación de las clases trabajadoras chilenas y la ruptura al interior de la burguesía, los elementos clave que permiten explicar la violencia que adoptó en Chile en cambio en el patrón de reproducción de capital. La ruptura al interior de la burguesía en Chile destruyó el sistema de dominación que articulaba un Estado burgués, lo que lleva al golpe de Estado, mientras por su parte, en México el cambio de proyecto se resuelve mediante los mismos engranajes del poder existentes, sin mediar una ruptura del sistema de dominación e iniciando una transición gradual pero sostenida.

\section{Bibliografía}

Aguilar, Alonso, Globalización y Capitalismo, México, Plaza y Janés,2002

Amin, Samir, Crítica de nuestro tiempo. A los ciento cincuenta años del Manifiesto comunista, México, Siglo XXI, 2001.

Arrollo, Juan Pablo, "Fundamentos y génesis de la política económica del Estado neoliberal en México, 1980-2010", en Ma. Eugenia Romero Sotelo (coord.), Fundamentos de política económica en México, 1910-2010, México, Facultad de Economía- UNAM - Colegio Nacional de Economistas, p. 427-526

Bulmer-Thomas, Victor, La historia económica de América Latina desde la Independencia, México, FCE, 2003

CEP varios autores, El ladrillo. Bases de la política económica del gobierno militar chileno, Santiago de Chile, CEP, 1992

Cuevas, Pablo, La 'ventaja' del asalariado rural latinoamericano: el trabajo silvoagropecuario en el actual patrón de acumulación de capital a través de los casos de Chile y México (Tesis doctoral), México, UNAM, 2017. Disponible en: 


\section{http://132.248.9.195/ptd2017/iunio/514350505/Index.html}

Cuevas, Pablo; Teresa Rojas, "El proceso neoliberal chileno a cuatro décadas del Golpe", en Estudios Latinoamericanos, nueva época, núm. 34, 2014, 75-94

Ffrench-Davis, Ricardo, Entre el neoliberalismo y el crecimiento con equidad; tres décadas de política económica en Chile, Buenos Aires, Siglo XXI editores, 2004.

Flores, Graciela; Luisa Paré y Sergio Sarmiento, Las voces del campo. Movimiento campesino y política agraria, 1976 1984, México, IIS-UNAM - Siglo XXI, 1988

Gárate, Manuel, La revolución capitalista en Chile (1973-2003), Santiago, Ediciones Universidad Alberto Hurtado, 2012, p.181

Garretón, M. Antonio, El proceso político chileno, Santiago de Chile, FLACSO, 1984.

Hardt, Michael y Antonio Negri, Imperio, Buenos Aires, Paidós, 2002

Harvey, David, "The 'new' imperialism: accumulation by dispossession", en Socialist Register, No. 40, 2004, pp. 64-87.

Harvey, David, Breve historia del neoliberalismo, Madrid, Akal, 2007

Hayek, Friedrich, Camino de servidumbre, Madrid, Alianza, 2007

Lenin, V.I., "Una Gran Iniciativa”, en Lenin, Obras escogidas en tres volúmenes, vol 3, Moscú, Progreso, 1966

López, Portillo, José, Mis tiempos: biografía y testimonio, México, Fernandez Editores, 1998.

Loveman, Brian y Lira, Elizabeth "La violencia política en Chile: Contextos y prácticas desde 1810”, en Iván Jaksic, Juan Ossa (editores), Historia política de Chile, 1910-2010, tomo I, prácticas políticas, Santiago de Chile, FCE-UAI, 2017

Marini, Ruy Mauro "Proceso y tendencias de la globalización capitalista", Ruy Muro Marini y Márgara Millán (eds.) La teoría social latinoamericana. Cuestiones contemporáneas. Tomo IV, México, Ediciones el caballito - UNAM, 1996, PP.49-68

Marini, Ruy Mauro, Dialéctica de la dependencia, México, Era, 1973.

Marini, Ruy Mauro, El reformismo y la contrarrevolución: Estudios sobre Chile, México, Era,1976 Marx, Karl, El Capital. Tomo III/Vol. 8, México, Siglo XXI, 1986

Meller, Patricio, Un Siglo de Economía Política Chilena (1890-1990), Santiago, Andrés Bello, 1998.

Oikión Verónica y García, María, Movimientos armados en México, siglo XX, Zamora, El Colegio de Michoacán, 2007.

Olave, Patricia, El proyecto neoliberal en Chile y la construcción de una nueva economía, México, IIEc-UNAM - El Caballito, 1997

Osorio, Jaime, Estado, biopoder y exclusión. Análisis desde la lógica del capital, Barcelona, Antropos - UAM-X, 2012.

Osorio, Jaime, Teoría marxista de la dependencia, México, ITACA - UAM-X, 2016.

Pablo Cuevas, "La crisis del patrón de legitimidad del Estado neoliberal chileno", en Argumentos, núm. 86, enero-abril, 2018, pp. 131-149.

Romero, Ma. Eugenia, “Las raíces de la ortodoxia en México”, en: Economía UNAM, no 24, p.2050

Rubio, Luis, "La reforma económica y el cambio político en México”, en Riordan Roett, (comp.), La liberalización económica y política de México, México, Siglo XXI, p. 59-80

Sotelo, Adrián, México (re)cargado: Dependencia, neoliberalismo y crisis, México, FCPyS-UNAM - Itaca, 2014 
Thielemann, Luis, "Movimientos obreros y movimientos sociales populares en Chile", en Iván Jaksic, Juan Ossa (editores), Historia política de Chile, 1910-2010, tomo I, Prácticas políticas, Santiago de Chile, FCE-UAI, 2017

Vergara, Pilar, Auge y caída del neoliberalismo en Chile: Estudio sobre la evolución ideológica del régimen Militar, Santiago de Chile, FLACSO, 1984, p.330

Wright Mills, Charles, La élite del Poder, México, Fondo de Cultura Económica, 1956

Zapata, Francisco, “Crisis económica y movilización social en Chile (1981-1984)”, en Foro Internacional, Vol. 26, No. 2 (102), p. 215

Base de datos World Development Indicators de Banco Mundial en: https://data.worldbank.org 